\title{
A Review of Leveraging Private Cloud Computing in Financial Service Institutions: Value Propositions and Current Performances
}

\author{
Keke Gai \\ College of Management \\ Lawrence Technological \\ University \\ Southfield, MI, 48075-1058, \\ USA
}

\begin{abstract}
This paper identifies main value propositions of leveraging private cloud computing and reviews current performance of implementing cloud computing technology in financial industry. The following aspects have been reviewed by this paper, namely (1) discerning cloud computing-enabled innovations, (2) identifying three value propositions of using cloud computing, (3) reviewing current performance of cloud computing in financial service institutions, and (4) sustainable competitive strategy of using cloud computing. The main contributions of this paper are twofold. First, this paper presents the implementations of cloud computing in financial industry and summarizes key enablers of leveraging cloud computing. Second, a strategy reference model was proposed for financial organizations to form sustainable competitive strategies via cloud-based solutions. The proposed reference model takes account into both shareholder value and stakeholder value. The adaptability of the model is in planning of being demonstrated in practice at the time of writing.
\end{abstract}

\section{Keywords}

Cloud Computing, Strategy Reference Model, Sustainability, Sustainable Competitive Strategy, Service-Oriented Architecture.

\section{INTRODUCTION}

Obtaining a competitive advantage is important to an enterprise, and sustainability is becoming one of significant competitive edges. Within the current global economic environment, an enterprise needs to understand how to gain a sustainable value that gives consideration to both shareholder value and stakeholder value. In addition, information technology (IT) innovation often plays a supporting role that creates or strengthens sustainable value for organizations. As a new computing model, cloud computing is able to bring positive impacts on value creation for enterprises in many situations.

This paper reviews cloud computing-enabled innovations and three value propositions related to financial service institutions (FSI). A review of nine FSIs is accomplished to understand current performance of private cloud computing in financial organizations. The review addresses two main aspects as follows:

1. Main value propositions of cloud computing and the corresponding benefits of value creations in FSIs to each value proposition.

2. The alignment of sustainability and private cloud-based solutions for FSIs.
This paper proposes a reference model representing the alignment of cloud computing with sustainability in financial industry based on the review. The structure of this paper is followed by cloud computing and cloud computing-enabled innovations, value proposition and benefit, current cloud computing performances in FSIs, sustainable competitive strategy, discussion, and conclusions.

\section{CLOUD COMPUTING AND ITS ENABLED INNOVATIONS}

Cloud computing is a new concept of leveraging Web-based technologies that provide users with a scalable service solution by offering multiple computing resources [1] [2] [3] [4]. Cloud computing services are categorized into a few service models. Three basic service models are Software-as-aService (SAAS), Platform-as-a-Service (PAAS), and Infrastructure-as-a-Service (IAAS) [4] [5]. Stenzel [6] defines these three basic service models as three layers of technology used in the cloud: applications and application development environments; data storage and database environments; and hardware virtualization. Virtualization of applications and infrastructure is often considered as the foundation of cloud computing [7].

With the different service models, cloud services are offered by several different deployment methods: private cloud; community cloud; public cloud; and hybrid cloud [4] [8]. Private cloud refers to the cloud infrastructure is owned, managed, leased, or operated by a single organization. Compared with other deployment method, private cloud computing can provide a safer cloud environment because this deployment method allows enterprises to take advantage of cloud computing behind their firewall. In addition, leveraging cloud computing brings organizations a number of benefits.

Quality cloud services can bring various benefits, such as driving business innovation, increasing responsiveness, reducing cost and improving asset utilization, providing a flexible IT environment, enabling in-time information sharing, and reaching resources globally [5]. These advantages facilitate emergence of the business enablers of cloud computing. A business enabler is an innovation model that leverages IT approaches to improve business processes, customer relationships, and supply chains [9]. Berman et al. [10] propose six business enablers of cloud computing: cost flexibility; business scalability; market adaptability; masked complexity; context-driven variability; and ecosystem connectivity. The benefits of using cloud computing are outcomes of various value propositions that represent the processes of adding value from different perspectives. The 
following section reviews three main value propositions related to using cloud computing including customer value, value chain, and service-oriented architecture (SOA).

\section{VALUE PROPOSITIONS}

A value proposition is a reference principle for pursuing a successful marketplace strategy that leverages technology innovation as an important approach of adding value [30]. In the field of financial services, three main value propositions related to using cloud computing include customer value, value chain, and service-oriented architecture.

\subsection{Customer Value Proposition}

The value proposition of customers provides a guiding principle positioning added value from the perspective of customers [10]. There are three basic customer value propositions: enhancement; expansion; and investment. Enhancement refers to how organizations can utilize cloud services to improve current products and enhance existing services. Expansion refers to how cloud services can help enterprises create new services or products. Investment refers to how cloud technology may be leveraged to create a new market that attracts new customers. Based on these three value propositions, customer relationships can be optimized by providing scalable solutions for matching customers' demands.

Glazer [31] developed a framework representing a hierarchy of generic customer benefits with a set of technological attributes related to the customer value propositions, which include customization, convenience, participation, and anticipation. This framework explains the main features of leveraging cloud-based solutions that add value via connecting customers with enterprises. Four aspects are highlighted including customized services, stable service supplier, efficient communications between customers and enterprises, and just-in-time information sharing and the ability to reach customers globally.

\subsection{Value Chain}

The value proposition of the value chain represents how cloud computing helps organizations improve or obtain advanced capability. Three main cloud-enabled value chain propositions are improvement, transformation, and creation [10].

The improvement value chain represents that the cloudenabled business model can strengthen an organization's capability in the existing value chain. This value proposition has been demonstrated in a number of industries, such as pharmacy industry and automotive manufacturing [32] [33].

Moreover, cloud computing technology can help companies to obtain new operating capabilities by the transformation of value chain because of the power of IT innovations. Cloud providers offer low-cost on-demand servers and cloud infrastructure services that can assist enterprises to quickly create new services leveraging Internet-based technologies [11].

Lastly, leveraging cloud computing technology can aid enterprises to develop new industry value chains in the form of cloud-enabled innovation creating new business models and services [12]. For example, a new managerial method for apartment management emerges based on leveraging Application-as-a-Service on the clouds [34]. This approach enables those apartment management companies who cannot afford servers to migrate data management to an applicationenabled model from a paper-based working model.
Figure 1 represents a value chain of using cloud computing in a FSI on an enterprise level. With the support of leveraging cloud computing, financial institutions can improve services in four domains, including services, finance, marketing, and operation. Primary activities are supported by four sides, namely technology support, business innovations and new services, operational capability, and strategic decision-making.

As displayed in Figure 1, leveraging private cloud computing may aid FSIs to lower service cost, provide environmentfriendly services, improve service environment, increase business agility, and optimize service quality. Next, in a perspective of finance, private cloud-based services can assist FSIs to reduce cost, increase asset utilization, and gain more customers' attention. Furthermore, private cloud-based solutions can help FSIs to avoid geographical restrictions, expand Internet-based business, increase online services' availability, and optimize services' updatability. Finally, considering the improvement of operation, leveraging private cloud computing can help FSIs to establish an operational system with the easy-to-learn advantage and the secured operational environment. The systems can be updated and maintained by cloud providers.

\begin{tabular}{|c|c|c|c|c|}
\hline \multirow{4}{*}{ 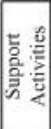 } & \multicolumn{4}{|c|}{ Technology Support } \\
\hline & \multicolumn{4}{|c|}{ Business Innovations \& New Services (Creation) } \\
\hline & \multicolumn{4}{|c|}{ Operational Capability (Transformation) } \\
\hline & \multicolumn{4}{|c|}{ Strategic Decision-Making (Improvement) } \\
\hline \multirow[b]{3}{*}{ 㤅 } & \multicolumn{4}{|c|}{ Service Improvement } \\
\hline & Services & Finance & Marketing & Operation \\
\hline & $\begin{array}{l}\text {-Lower price } \\
\text {-Green services } \\
\text {-Better service } \\
\text { environment } \\
\text {-Agility } \\
\text {-Optimize } \\
\text { service }\end{array}$ & $\begin{array}{l}\text {-Affordable } \\
\text {-Asset utilization } \\
\text {-More revenue } \\
\text {-Customer value }\end{array}$ & $\begin{array}{l}\text {-Geographically } \\
\text { reachable } \\
\text {-Internet-based } \\
\text { marketing } \\
\text {-Availability } \\
\text {-Updatability }\end{array}$ & $\begin{array}{l}\text {-Operational } \\
\text { system } \\
\text {-Easy-to-learn } \\
\text { (train) } \\
\text {-Security } \\
\text {-Updatable } \\
\text { system }\end{array}$ \\
\hline
\end{tabular}

Fig 1: Value chain of using cloud computing in a financial service institution

Understanding the value chains and main activities or processes can support the formulation of the sustainable competitive strategy.

\subsection{Service-Oriented Architecture}

Cloud computing is often combined with SOAs since the common purpose of leveraging cloud computing is to offer services [8]. A service-oriented architecture (SOA) is a strategic framework with a full set of principles and methodologies to develop applications that offer customers Internet-based services [13]. Luthria et al. [14] proposed a stakeholder value model for SOA that aims to align service requirements with business strategy. The model consists of three value propositions: strategic value; tactical value; and operational value.

The strategic value emphasizes the service delivery platform. A cloud-based SOA can integrate external and internal sources for improving collaborations on an enterprise level [15]. For example, enterprises build up a strategic partnership based on a pay-as-you-go model [8]. In addition, a cloudbased SOA supports the existing IT infrastructure [16][17].

The tactic value proposition emphasizes agility in business processes, which enables dynamic capabilities by a flexible plug-and-play model [18]. The agility is represented in three aspects: process flexibility, portability, and adoption [14]. A higher-level agility can aid companies to simplify the process of entering market, avoid restrictions of geographic locations, and reduce risks [8] [35] [36]. 
The operational value proposition focuses on the enhancement of business processes efficiency [14]. This value proposition is embodied in the following aspects: process improvement, process visibility, development of potential revenue streams, cost-friendly, and rapid development of new products. Cloudbased SOAs achieve these values relying on the flexibility characteristic of cloud computing. Without hosting own servers, enterprises can introduce their new products or services in a shorter-time.

\section{CLOUD COMPUTING PERFORMANCE IN FINANCIAL SERVICE INSTITUIONS}

With the development of Internet-based technologies, cloudbased solutions are becoming popular approaches for FSIs to improve or create services [19]. Compared with large sized FSIs, cloud-based solutions are much easier to be accepted by smaller sized organizations. Based on a survey result focusing on FSIs in Europe, the Middle Ease, and Africa, 44 percent of financial service institutions expect to migrate more than half of their transactions to cloud infrastructure by 2015 , and 33 percent of them anticipate most transactions will be processed via cloud applications by 2015 [20]. It implies that migrating to the cloud may become a mainstream for FSIs to improve or create services.

For moving to the cloud, three main service models include IAAS, SAAS, and PAAS [21]. IT infrastructure in the cloud can be either physical IT equipment or virtualized machines, which provide enterprises with a flexible pattern of investing infrastructure. Moreover, software running in the cloud is a service model that provides financial institutions with opportunities to examine whether their transactions should be moved to the cloud [22]. The process of cloud computing adoption is a gradual process that usually starts with a lowerlevel service. Cochran, a small state bank in Georgia State, provides a successful example of adopting cloud-based services from starting with low level services [22]. Additionally, the PAAS can help FSIs quickly understand whether new services are adapted by customers [29]. Risks may be lowered because of the efficient web-based service development time.

The primary intent of leveraging private cloud computing for small or medium-sized FSIs is to reduce investment cost and accelerate business development [23]. FSIs can document all technical problems and send them to cloud providers so that they can effectively utilize their limited resources to expand their businesses. Considering the privacy issues, many financial firms prefer running private clouds to keep their clients' information behind their own firewall [24]. However, this choice weakens some of the advantages of cloud computing because the organizations still need to host servers. Moving servers to the cloud will become more commonly used for private clouds in the financial service industry [25]. It depends on whether cloud providers can offer a higher-level security service.

On the basis of the case studies for seven small/medium size FSIs leveraging private cloud computing, SAAS, IAAS, and PAAS are three main service models for FSIs [22] [37] [38] [39] [40] [41] [42]. The top three business enablers are cost flexibility, market adaptability, and masked complexity. It implies that financial institutions emphasize three aspects when they move to the clouds, which are cost, functionality, and efficiency. Figure 2 displays seven main key values when seven small/medium size FSIs deployed private cloud computing. The radar chart illustrates the importance level among seven business enablers' performances. The number in the radar chart means the amount of FSIs that considered each business enabler as the key value of using private cloud computing.

Cost flexibility refers to FSIs either reduce cost on technology innovations or reduce expense on employment by deploying private cloud computing [22] [37] [38] [39]. Cost saving is a common attraction for FSIs to migrate their servers to cloud providers. Meanwhile, market adaptability is the next major business enabler. For example, leveraging private cloud computing can assist a FSI to achieve a global virtualized high-performance IT infrastructure for global markets in a short period [38]. The flexible solutions can aid FSIs to easily adjust services and rapidly expand their business scopes [41]. Moreover, masked complexity can assist FSIs to acquire at least two benefits, including risk migration and concentrating on services [22] [37] [41] [42]. The security concern is always a great issue in implementing cloud-based solutions, which results in a cautious migration. According to the results of the case study, all seven financial institutions migrate their servers to the clouds in the form of gradually transfer. When risks are migrated to cloud providers, FSIs can concentrate on improving the existing services or creating new services.

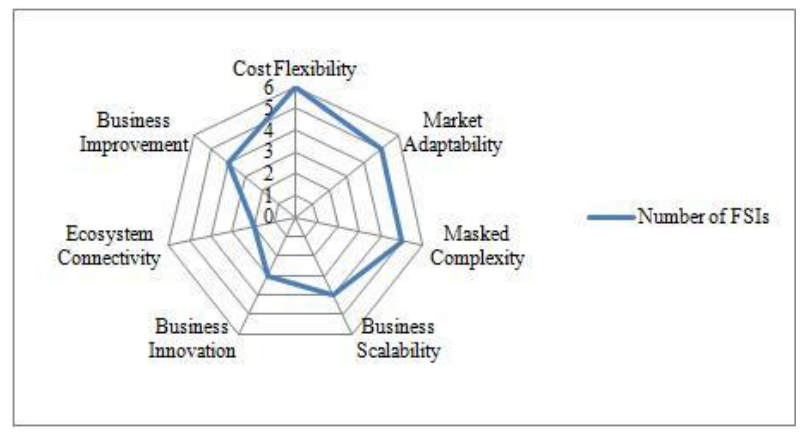

Fig 2: Value chain of using cloud computing in a financial service institution

In summary, leveraging private cloud computing in financial industry can be considered as a strategy issue that requires FSIs to discern business enablers and security concerns.

\section{SUSTAINABLE COMPETITIVE STRATEGY OF CLOUD COMPUTING}

A competitive strategy can be created by positioning products or services in the market [26] [27]. Enterprises need to address the advantages of the products or services in price, quality, or special target customers. When small and mediumsize FSIs are engaging in creating or improving services, the obstacles of the changes are financial restrictions and time. Leveraging private cloud computing can assist FSIs to focus on positioning their services because cloud-based solutions cut down the costs and development time.

The concept of sustainable value is a dynamic value creation that is beneficial for both shareholder value and stakeholder value, which is a natural outcome of the new environment caused by three trends, namely declining resource, radical transparency, and increasing expectations [28]. The trends are caused by environmental changes and technological innovations, which implies a sustainable strategy is a necessity for enterprises to adapt to current business environment.

A sustainable strategy requires enterprises to consider their competitive strategies in a long-term perspective. Laszlo and Zhexembayeva [28] proposed a generic strategy model that 
explained the approaches of obtaining sustainability. The model states that sustainability can result in a number of advantages but it commonly increases costs. The conflicts between the costs and other positive outcomes require enterprises to find a strategy taking into account both sustainability and immediate interests. Leveraging private cloud computing can provide a feasible approach for avoiding the conflicts. Aligning sustainable competitive strategies with the value propositions of cloud computing, a reference model is proposed for understanding the alignment of cloud computing and sustainability in FSI, which is represented in Figure 3 .

Figure 3 represents an alignment of sustainability with cloud computing in FSIs. As shown in the figure, seven generic approaches of creating value are risk mitigation, efficiency enhancement, differentiation factor, new markets opportunities, reputation improvement, impacts on industry standards, and radical innovation activities. Leveraging cloud computing in FSIs can assist institutions to practice these approaches and achieve sustainability by the advantages of the technology. Each generic approach is aligned with a set of value propositions of using cloud computing. Moreover, cloud computing makes it possible to acquire both sustainability and cost reduce synchronously.

This strategy reference model provides enterprises who intend to achieve sustainability with a theoretical guideline in financial industry. It introduces an approach of aligning sustainability with both shareholder value and stakeholder value by leveraging cloud-based solutions. The model will be beneficial for strategic decision-making when enterprises determine to implement a sustainable competitive strategy.

\begin{tabular}{|c|c|}
\hline \multicolumn{2}{|r|}{ Financial Industry } \\
\hline Sustainability & Cloud Computing Performance \\
\hline Radical Innovation & $\begin{array}{l}\text { New productsiservices, shorter-time } \\
\text { development }\end{array}$ \\
\hline $\begin{array}{l}\text { Impact of Industry } \\
\text { Standards }\end{array}$ & $\begin{array}{l}\text { Customer value proposition, value chain, } \\
\text { business innovation }\end{array}$ \\
\hline $\begin{array}{l}\text { Improvement of } \\
\text { Reputation }\end{array}$ & $\begin{array}{l}\text { Ecosystem comnectivity, customer value } \\
\text { proposition, employee value }\end{array}$ \\
\hline $\begin{array}{l}\text { Opportunity of New } \\
\text { Markets }\end{array}$ & $\begin{array}{l}\text { Context-driven variability, value chain, flexible } \\
\text { IT environment }\end{array}$ \\
\hline $\begin{array}{c}\text { Factor of } \\
\text { Differentiation }\end{array}$ & $\begin{array}{l}\text { Customer value proposition, value chain, market } \\
\text { adaptability }\end{array}$ \\
\hline $\begin{array}{l}\text { Enhancement of } \\
\text { Efticiency }\end{array}$ & $\begin{array}{l}\text { Business innovation, market adaptability. } \\
\text { masked complexity, value chain }\end{array}$ \\
\hline Risk Mitigation & Mitigate risks to cloud providers \\
\hline $\cos \mathrm{T}$ & Cost flexibility and reduce cost \\
\hline
\end{tabular}

Fig 3: Alignment of sustainability with cloud computing in financial industry

\section{DISCUSSION}

Small/medium size FSIs leverage private cloud computing in order to expand their service scopes and strengthen the existing services with an affordable price. Due to the concern of security, most FSIs move their data management to cloudbased servers in a gradual manner. This manner provides FSIs with a chance to examine whether the cloud-based servers meet their expectations. The results of the investigation on leveraging private cloud computing in financial industry display that there are a number of successful cases in the field. FSIs are more likely strategic decision makers who need to cognize their organizations' demands, concerns, and goals.
With leveraging private cloud computing, FSIs can pay more attention to their services and customers because software development work and risks have been migrated to cloud providers. The role of cloud providers is diversified. For example, a cloud provider may be an intelligent automation manager, may be a facilitator opening global markets, and may be an operator of service providers [37] [38] [40].

In addition, many current FSIs have cognized the importance of sustainability, which is considered as one of criteria of decision-making [43] [44]. The proposed framework in this paper provides enterprises with an approach of aligning sustainability with leveraging private cloud computing in financial industry. Moreover, the alignment avoids the conflict between cost and sustainability. The adaptability of the model is in planning of being demonstrated in practice at the time of writing.

\section{CONCLUSION}

The main contributions of this paper are twofold. First, the paper reviews three main value propositions of leveraging cloud computing, including customer value, value chain, and SOA. These value propositions identify the main activities and concerns within a process of strategy-making. Considering the importance of security issues, current FSIs mostly choose private cloud computing as the deployment method. The primary concerns of investing in cloud-based solutions are cost and development time. Second, a reference model was developed for aligning sustainability with both shareholder value and stakeholder value by using private cloud computing. The model derives from Laszlo and Zhexembayeva's [28] generic strategy model that formulates a few aspects that are considerable for sustainability. The proposed model introduces a new approach that solves the conflicts between costs and sustainability. With the technology support of leveraging cloud computing, FSIs can form a sustainable competitive strategy without increasing costs.

A few questions for further consideration are (1) what would be the actual performance of the proposed strategy reference model? And (2) can the proposed reference model be generalized in other industries?

\section{REFERENCES}

[1] K. Gai, and S. Li, "Towards cloud computing: A literature review on cloud computing and its development trends," in the Fourth International Conference on Multimedia Information Networking and Security. IEEE, 2012, pp. 142-146.

[2] J. Geelan, "Twenty-one experts define cloud computing," Cloud Computing Journal, vol. 2 (2009): pp. 1-5, 2009.

[3] K. A. Jamsa, Cloud Computing: SaaS, PaaS, IaaS, Virtualization, Business Models, Mobile, Security and More. Jones \& Bartlett Publishers, 2012.

[4] P. Mell, and T. Grance. "The NIST definition of cloud computing (draft)," NIST Special Publication, vol. 800, (145) 2011

[5] H. Muller, On top of the cloud: How CIOs leverage new technologies to drive change and build value across the enterprise, Wiley Publisher, 2011.

[6] J. Stenzel, CIO best practices: Enabling strategic value with information technolog, New York: John Wiley \& Sons, 2011. 
[7] J. Sorofman, "How to achieve the strategic value of cloud while delivering real ROI," (eWeek), [onlne] 2009, http://www.eweek.com/c/a/Cloud-Computing/How-toAchieve-the-Strategic-Value-of-Cloud-while-DeliveringReal-ROI/ (Accessed: March 03, 2009).

[8] D. S. Linthicum, Cloud Computing and SOA Convergence in your Enterprise: A Step-by-Step Guide. Addison-Wesley Publications, 2011.

[9] J. W. Weiss, A. Thorogood, and K. D. Clark, "Three ITbusiness alignment profiles: Technical resource, business enabler, and strategic weapon," Communications of the Association for Information Systems, vol. 18 (1) pp. 33, 2007.

[10] S. J. Berman, L. Kesterson-Townes, A. Marshall, and R. Srivathsa, "How cloud computing enables process and business model innovation," Strategy \& Leadership, vol. 40, (4) pp. 27-35, 2012.

[11] IWeb.com launches new "kinder" cloud computing service., PRWeb, [online] 2012, http://www.prweb.com/releases/2012/4/prweb9373786.ht m (Accessed: April 10, 2012)

[12] A. B. Mohammed, J. Altmann, and J. Hwang. "Cloud computing value chains: Understanding businesses and value creation in the cloud," in Economic Models and Algorithms for Distributed Systems. Birkhäuser Basel, 2010, pp. 187-208.

[13] J. P. Lawler, and H. Howell-Barber, Service-oriented Architecture: SOA Strategy, Methodology, and Technology, CRC Press, 2007.

[14] H. Luthria, A. Aurum, G. C. Low, and F. A. Rabhi, "Aligning service requirements with business strategy: A proposed stakeholder value model for SOA," in 2008 Information System Development, 2009, pp. 149-156.

[15] M. Bohlouli, A. Holland, and M. Fathi. "Knowledge integration of collaborative product design using cloud computing infrastructure," in 2011 IEEE International Conference on Electro/Information Technology (EIT). IEEE, 2011.

[16] C. D. Huang, and Q, Hu, "Integrating web services with competitive strategies: the balanced scorecard approach," Communications of AIS, vol. 13, (2004) pp. 57-80, 2004.

[17] H. J. La, S. H. Oh, and S. D. Kim, "Methods to utilizing cloud computing in developing mobile internet device (MID) applications," in the fourth International Conference on Uniquitous Information Management and Communication, ACM, 2010, pp. 31.

[18] H. Luthria, F. Rabhi, and M. Briers. "Investigating the potential of service oriented architectures to realize dynamic capabilities," In the Second IEEE Asia-Pacific Service Computing Conference, IEEE, 2007, pp. 390397.

[19] R. Gill, "Why cloud computing matters to finance," Strategic Finance, vol. 92, (7) pp.43-47, 2011.

[20] Cloud computing impacting financial services specialists Gartner, eWeek, [online] 2011, http://business.highbeam.com/137475/article-1G1271383121/cloud-computing-impacting-financialservices-specialists (Accessed: November 1, 2011)
[21] V. Suma, D. Bhagavant, M. Vaidehi, and T. R. G. Nair, "Cloud computing for microfinances," in International Conference on Systemics, Cybernetics and Informatics, 2012, pp. 159-160.

[22] J. Quittner, "Small banks trying cloud computing find benefits," American Banker, vol. 176 (94) pp. 10, 2011.

[23] CCID consulting: Cloud computing application market driven by small and medium-sized financial institutions in China, Business Wire, [online] 2012 http://www.businesswire.com/news/home/201208310051 99/en/CCID-Consulting-Cloud-Computing-ApplicationMarket-Driven (Accessed: August 31, 2012).

[24] I. Schmerken, "The rise of the financial services cloud," Wall Street \& Technology, vol. 30 (1) pp. 6, 2012.

[25] R. D. Kugel, "Finance in the cloud," Business Finance, vol. 15, (5) pp. 3, 2009.

[26] W. B. Gartner, "Competitive strategy / competitive advantage," The Academy of Management Review (Pre1986), vol. 10, (000004), 873-873, 1985.

[27] M. E. Porter, Competitive Strategy, New York: Free Press, 1985.

[28] C. Laszlo, and N. Zhexembayeva, Embedded sustainability: The next big competitive advantage. Sheffield: Greenleaf Publishing, 2011.

[29] C. Babcock, "Platform as a service," Information Week, vol. 1243, pp. 18-20, 22-23, 2009.

[30] M. Treacy, and F. Wiersema, The Discipline of Market Leaders. New York, NY: Simon and Schuster, 1995.

[31] R. Glazer. "Meta-technologies and innovation leadership: Why there may be nothing new under the sun," California Management Review, vol. 50, (1) pp.120-143, 2007.

[32] V. Garg, S. Arora, and C. Gupta. "Cloud computing approaches to accelerate drug discovery value chain," Combinatorial Chemistry \& High Throughput Screening, vol. 14, pp. 861-871, 2011.

[33] PR Newswire. "Audi selects IBM to migrate SAP infrastructure to cloud," PR Newswire, Apirl 2011.

[34] P. Helland, "Constraints in an environment empower the services: Condos and clouds," Communications of the $A C M$, vol. 56, (1), pp. 50-59, 2004

[35] L. Mearian. "NYSE lanuches cloud service for Wall Street," Computerworld, vol. 2, June 20, 2011.

[36] J. Hagel, and J. S. Brown. "Your next IT strategy," Harvard Business Review, vol. 79, (9), pp. 105-115, 2001.

[37] Telecommunications Weekly. "Intelligent automation: The world's leading financial institution selects adaptive computing technology for revolutionary new private cloud strategy," Telecommunications Weekly, April 20, 2011.

[38] PR Newswire. "UniCredit global information systems S.P.A global markets \& amp: Treasury selects platform computing to deliver a private cloud environment," $P R$ Newswire, Nov. 22, 2011.

[39] M2 Presswire. "Orange business services - Trading solutions enters a ear of cloud trading; Flexible trading 
service offers "pay as you grow' solution to financial institutions," M2 Presswire, June 19, 2012.

[40] F. Foo, and M. Sharma. "Bank looking to the cloud to blow away software licensing costs," The Australian, pp. 33-34, Oct. 2009.

[41] PR Newswire. "Cloud-based core banking becomes a reality in Kenya," PR Newswire, Oct. 11, 2012.
[42] Telecommunications Weekly. "Wolters Kluwer Financial Services: Moving secure document exchange to cloud," Telecommunications Weekly, pp. 229, Dec. 14, 2011.

[43] D. O. Raluca. "The strategic importance of corporate responsibility and sustainability in banking," Analele Universităţii Constantin Brâncuşi din Târgu Jiu. Seria Economie, vol. 1, (1), pp.193-199, 2013.

[44] G. Minassian. "Bulgarian banking: Looking for sustainability," Contemporary Economics, vol. 7, (3), pp.1-124, 2013. 